\title{
SELETIVIDADE DA CULTURA DO MILHO AO HERBICIDACLOMAZONE POR MEIO DO USO DE DIETHOLATE
}

\author{
DÉCIO KARAM ${ }^{1}$, ANDREA ALMEIDA CARNEIRO ${ }^{1}$, LÚCIA H. ALBERT ${ }^{2}$, MICHELLE \\ BARBEIRO DA CRUZ ${ }^{3}$, GRACIELLE T. COSTA ${ }^{4}$, PAULO CÉSAR MAGALHÃES ${ }^{1}$
}

\author{
${ }^{1}$ Pesquisadores, Embrapa Milho e Sorgo. Caixa Postal 151, CEP 35701-970 Sete Lagoas, MG. E-mail: \\ karam@cnpms.embrapa.br (autor para correspondência). \\ ${ }^{2}$ Doutoranda em Fitotecnia, Universidade Federal de Lavras. Caixa Postal 37, CEP 37200-000 Lavras, MG. \\ ${ }^{3}$ Graduanda em Ciências Biológicas, Unicentro Izabela Hendrix. Belo Horizonte, MG. \\ ${ }^{4}$ Graduanda em Ciências Biológicas, PUC-MG. Belo Horizonte, MG.
}

Revista Brasileira de Milho e Sorgo, v.2, n.1, p.72-79, 2003

\begin{abstract}
RESUMO - Com o objetivo de avaliar a seletividade de clomazone na cultura do milho através do uso de dietholate, foram instalados dois experimentos, sob condições de casa-devegetação e laboratório, na Embrapa Milho e Sorgo, Sete Lagoas, MG. Sementes do milho BRS 2223 foram tratadas ou não com dietholate, na proporção de $500 \mathrm{~g}$ para $100 \mathrm{Kg}$ de semente. Os tratamentos herbicidas foram oito doses de clomazone $(0,0 ; 62,5 ; 125,0 ; 250,0$; 500,$\left.0 ; 1000,0 ; 2000,0 ; 4000,0 \mathrm{~g} \mathrm{ha}^{-1}\right)$. As plantas de milho provenientes de sementes não tratadas com dietholate apresentaram índices estimados de 50\% de fitotoxicidade, aos 14 DAA, em função da dose de $1203 \mathrm{~g} \mathrm{ha}^{-1}$ de clomazone, enquanto que esse índice somente foi estimado nas plantas de milho provenientes de sementes tratadas com dietholate, em função da dose de $1921 \mathrm{~g} \mathrm{ha}^{-1}$ de clomazone. As diferenças no acúmulo de matéria seca aérea das plantas de milho tratadas ou não com dietholate foram observadas a partir da dose de $2000 \mathrm{~g}$ ha $^{-1}$ de clomazone. Reduções de $80 \%$ e $90 \%$ no acúmulo da matéria seca aérea foram detectadas com a dose de clomazone a $4000 \mathrm{~g} \mathrm{ha}^{-1}$, em plantas provenientes de sementes tratadas ou não com dietholate, respectivamente. $O$ teor de clorofila foi reduzido em $50 \%$ com a dose de $784 \mathrm{~g} \mathrm{ha}^{-1}$ e $1740 \mathrm{~g} \mathrm{ha}^{-1}$, em plantas provenientes de sementes com ou sem dietholate, respectivamente. Em experimento in vitro, sementes tratadas na mesma proporção com dietholate foram crescidas em meio de cultura com a adição de clomazone $(4,8,16,32$ e 64 ppm). As reduções estimadas do teor de clorofila nas plantas in vitro foram de $31,1 \%$ e 83,9, para as plantas provenientes de sementes tratadas ou não com dietholate, respectivamente. Os resultados permitem inferir que o uso do protetor de sementes dietholate aumenta a seletividade de cultivares de milho ao herbicida clomazone.
\end{abstract}

Palavras-chave: toxicidade, antídoto, dose resposta, herbicida, safener.

\section{CLOMAZONE SELECTIVITY IN CORN (ZEAMAYS) OBTAINNED WITH THE USE OF DIETHOLATE}

\begin{abstract}
The objective of this work was to evaluate the clomazone selectivity of corn plants treated previously with dietholate. For this purpose, two experiments were set up in green house and laboratory at Embrapa Milho e Sorgo, Sete Lagoas, MG. Corn seeds BRS 2223 were treated with dietholate at $500 \mathrm{~g}$ to $100 \mathrm{Kg}$ of corn seeds. Herbicide treatments consisted of 8 different rates of clomazone $(0.0 ; 62.5 ; 125.0 ; 250.0 ; 500.0 ; 1000.0 ; 2000.0$; 4000.0 g.ha-1) plus a control treatment. Corn plants originated from untreated seeds showed
\end{abstract}


a estimated 50\% phytotoxicity index 14DAA due to $1203 \mathrm{~g} \cdot \mathrm{ga}^{-1}$ clomazone rate. Nevertheless, in the case of plants originated from treated seeds, presented the same $50 \%$ index only at 1921 $\mathrm{g} \mathrm{ha}^{-1}$ clomazone rate. The shoot dry weight difference between corn plants from treated and untreated seeds was observed only after 2000 g.ha ${ }^{-1}$ of clomazone rate. Shoot dry weight reductions of $80 \%$ and $90 \%$ for plants treated and untreated seeds, respectively, were obtained at 4000 g.ha ${ }^{-1}$ of clomazone rate. The chlorophyll content had a 50\% decrease at 784 g.ha $^{-1}$ and $1740 \mathrm{~g}^{\mathrm{g}} \mathrm{ha}^{-1}$ clomazone rate for plants from treated and untreated seeds respectively. In an in vitro experiment, seeds treated at the same dietholate rate, were grown in culture medium added with clomazone $(4,8,16,32$ and $64 \mathrm{ppm})$. The estimated reductions in the chlorophyll contend for the in vitro plants were respectively $83,9 \%$ and $31,1 \%$ for plants grown from treated and untreated seeds. These results showed that dietholate safener increases the selectivity of corn plants to clomazone.

Key words: toxicity, antidote, response dosage, herbicide, safener.

Clomazone, herbicida pertencente ao grupo químico das isoxazolinonas, é registrado atualmente no Ministério da Agricultura, Pecuária e Abastecimento para as culturas do arroz irrigado, algodão, cana de açúcar, batata, fumo, mandioca e soja (Brasil, 2002).

Indicado para aplicações em pré-emergência no controle de gramíneas anuais e algumas folhas largas, possui residualidade no solo, impedindo a emergência das espécies que lhe são suscetíveis, por 100 a 120 dias. Clomazone pode provocar fitotoxicidade temporária em cereais de inverno, como o trigo, a aveia e o centeio, enquanto que para as culturas do girassol, milho, hortícolas e citros essa fitotoxicidade pode ser não reversível.

A seletividade de um herbicida à cultura está relacionada a uma série de fatores, como características do produto, das plantas e métodos de aplicação (Oliveira Jr., 2001), sendo determinada pela tolerância diferenciada que as plantas apresentam à ação do composto, a existência de obstáculos maiores ou menores à sua entrada no sistema, diferenças no tempo e intensidade de exposição de partes da planta ao mesmo, assim como diferenças na metabolização do produto (Deuber, 1992).

Embora a seletividade a herbicidas possa estar associada à absorção, translocação ou metabolismo do produto, esses mecanismos às vezes não esclarecem, de forma adequada, diferenças de respostas observadas entre as espécies (Liebl \& Norman, 1991).

Na década de 60, Hoffman (1962) introduziu a idéia do aumento da seletividade de plantas a herbicidas através do uso de substâncias químicas, chamadas de antídotos ou "safeners", que podem ser utilizadas na forma de tratamento da semente ou em mistura com o herbicida, na calda de pulverização. Entretanto, na aplicação em mistura com o herbicida, deve-se tomar o cuidado para que não haja o favorecimento da planta daninha em detrimento dessa proteção (Hess \& Weller, 2000).

Devido à sua habilidade de aumentar a seletividade da cultura, os antídotos têm distintos potenciais de uso, que incluem a proteção das culturas contra os danos causados por resíduos de herbicidas e o uso de herbicidas sob condições adversas, onde é provável ocorrer dano à cultura (Davies \& Caseley, 1999).

Antídotos protegem culturas gramíneas do dano do herbicida pela redução na habilidade das moléculas do produto em atingirem e ligarem-se ao local de ação na cultura (Kotoula-Syka \& Hatzios, 1996). Esses autores demonstraram que a tolerância do milho aos herbicidas do grupo químico das sulfoniluréias pode ser aumentada com o uso do 
antídoto AN (1,8 anidrido naftálico). Teoricamente, o aumento da tolerância ao uso de antídotos pode ser conseguido por estímulo do metabolismo do herbicida em enzimas-alvo, redução na absorção e translocação do herbicida ou metabolização do herbicida a compostos menos tóxicos (Davies \& Caseley, 1999).

A evolução no conhecimento do mecanismo de ação dos antídotos e a associação de sua ação com processos de detoxificação de herbicidas fazem com que seja esperada a ocorrência de ação protetora para uma gama maior de herbicidas, como clomazone, diclofop, sulfentrazone e isoxaflutole, eficientes no controle de gramíneas (Rizzardi \& Serafini, 2001).

Dentre os antídotos ou "safeners" relacionados à proteção da fitotoxicidade a herbicidas, encontra-se o dietholate (0,0-diethyl 0 -phenyl phosphorothioate) que pertence ao grupo químico éster do ácido fosfórico, registrado com o nome comercial de Permit (500 $\mathrm{g}$ de dietholate $\left.\mathrm{kg}^{-1}\right)$ junto ao Ministério da Agricultura, Pecuária e Abastecimento, sob o número de registro 00801 , de $8 / 2001$ (Brasil, 2002).

Com o objetivo de avaliar a seletividade de clomazone à cultura do milho, com ou sem a adição de dietholate, foram instalados experimentos em condições de casa-de-vegetação e laboratório, na Embrapa Milho e Sorgo, em Sete Lagoas, MG.

\section{Material e Métodos}

\section{Casa de vegetação}

Dois experimentos foram conduzidos em condições de casa-de-vegetação (20/03/2002 e 02/ 04/2002), na Embrapa Milho e Sorgo, em Sete Lagoas, MG. Vasos com capacidade de 1,0 L foram preenchidos com terra proveniente da camada superficial de um latossolo vermelho distrófico, textura argilosa (LVd), adubado de acordo com a análise do solo. Sementes do milho BRS 2223 foram tratadas ou não com dietholate, na proporção de $500 \mathrm{~g}$ para $100 \mathrm{Kg}$ de semente, sendo três sementes semeadas em cada vaso. Os tratamentos foram dispostos em esquema fatorial $(8 \times 2)$, utilizando-se o delineamento de blocos ao acaso, com quatro repetições, sendo que cada vaso foi considerado uma unidade experimental. Os tratamentos com herbicidas foram constituídos de oito doses de clomazone $(0,0 ; 62,5 ; 125 ; 250 ; 500 ; 1000 ; 2000$; $\left.4000 \mathrm{~g} \mathrm{ha}^{-1}\right)$. Os herbicidas foram pulverizados com o uso de um pulverizador pressurizado $\mathrm{CO}_{2}$, operando à pressão constante de $40 \mathrm{lb} \mathrm{pol}^{-2}$, munido de bico Teejet 110-02 e consumo de calda de $190 \mathrm{~L} \mathrm{ha}^{-1}$. Avaliações visuais de fitotoxicidade foram realizadas aos 7 e 14 dias após a emergência (DAE), tomando-se como referência a escala de 0 (nenhum sintoma) a $100 \%$ (morte ou dano total das plantas). No experimento instalado em $02 / 04 / 2002$, foi determinado o teor de clorofila nas plantas de milho, aos dez dias após o plantio, utilizando-se um medidor de clorofila Spad 502 da Minolta. Os dados resultantes das avaliações foram submetidas à análise de variância e análise de regressão.

\section{In vitro}

Sementes de milho BRS 2223 foram esterilizadas em $50 \%$ de hipoclorito de sódio e $0,01 \%$ Tween 20, durante 45 minutos, sob agitação contínua, sendo, em seguida, enxaguadas três vezes, com água destilada estéril. As sementes esterilizadas foram tratadas ou não com dietholate, na proporção de 500 g para cada $100 \mathrm{Kg}$ de sementes, e cultivadas em Magentas boxes contendo meio MS (Murashige \& Skoog, 1962) $\left[4,3 \mathrm{~g} \cdot \mathrm{L}^{-1} \mathrm{MS}\right.$ sais (Sigma), $10 \mathrm{~g}$ mio-inositol, $1 \mathrm{~g}$ tiamina- $\mathrm{HCl}, 0,1 \mathrm{~g}$ ácido nicotínico, $0,1 \mathrm{~g}$ piridoxina, $30 \mathrm{~g} \cdot \mathrm{L}^{-1}$ sacarose, $0,8 \%$ ágar] acrescido ou não de solução de clomazone, esterilizada por filtração, nas concentrações de $0,4,8,16,32$ e 64 ppm. As sementes não tratadas com dietholate foram também cultivadas em meio MS acrescido de clomazone, nas concentrações citadas anteriormente. As plantas foram mantidas em 
sala de crescimento com fotoperíodo de 16 horas, durante 20 dias, e desenvolveram-se normalmente. Para a análise do teor de clorofila das plantas aos 21 DAA, foi utilizado um medidor de clorofila Spad 502 da Minolta. Os tratamentos foram dispostos em delineamento inteiramente casualizado em esquema fatorial 6 (dose de clomazone) x 2 (tratamento ou não da semente com dietholate). Análise de variância e regressões foram realizadas.

\section{Resultados e Discussão}

A comparação das variâncias dos experimentos através do teste de Bartlett indicou não haver diferenças entre experimentos; portanto, os dados observados foram agrupados e analisados conjuntamente (Steel et al., 1997). Através da análise de variância conjunta, foi detectado efeito significativo da interação dose de clomazone e o tratamento de sementes, sendo, portanto, realizadas as análises de regressão por tratamento ou não das sementes com dietholate.

Os resultados de fitotoxicidade podem ser observados na Figura 1. Aos sete dias após a aplicação (DAA), o tratamento das sementes com dietholate reduziu significativamente o efeito tóxico de clomazone, embora essas diferenças tenham sido melhor observadas com as doses intermediárias do herbicida (Figura $1 \mathrm{~A}$ ). Provavelmente devido à absorção gradativa do protetor, o mecanismo de desintoxicação do produto pelas plantas de milho aumentou, apresentando diferenças significativas apenas a partir de $1000 \mathrm{~g} \mathrm{ha}^{-1}$ aos 14DAA (Figura 1 B).
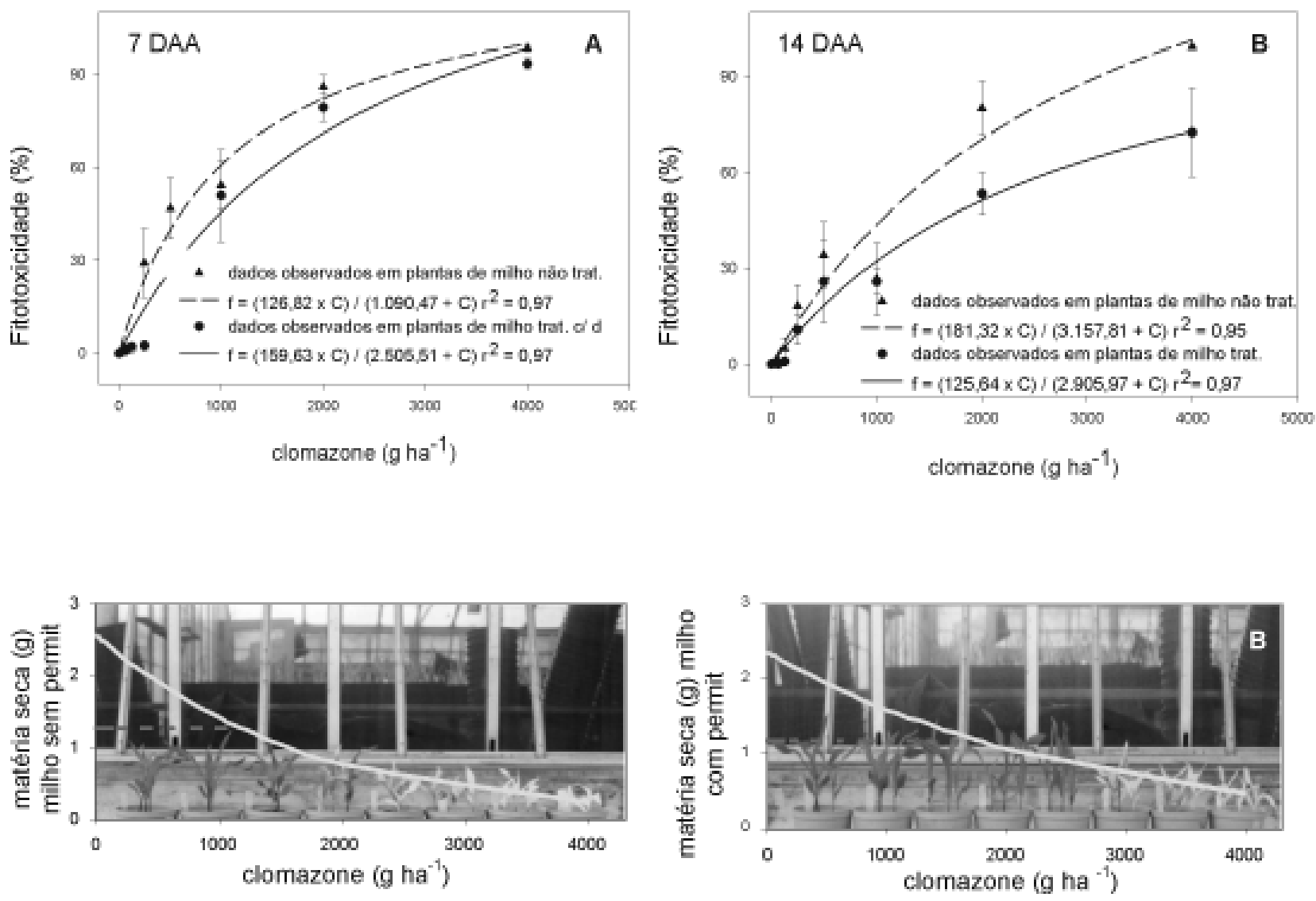

FIGURA 1. Efeito de clomazone no híbrido de milho BRS 2223 tratado ou não com dietholate. Embrapa Milho e Sorgo, Sete Lagoas, MG, 2002. 
Essas diferenças podem ser nitidamente visualizadas quando comparam-se as doses que induziram sintomas visuais de $50 \%$ de fitotoxicidade $\left(\mathrm{I}_{50}\right)$. As plantas de milho provenientes de sementes não tratadas com dietholate apresentaram índices estimados de $50 \%$ de fitotoxicidade, em função da dose de 1.203 $\mathrm{g} \mathrm{ha}^{-1}$ de clomazone, enquanto que esse índice somente foi observado nas plantas de milho provenientes de sementes tratadas com dietholate, em função da dose de $1.921 \mathrm{~g} \mathrm{ha}^{-1}$ de clomazone (Figura 1).

Os resultados de fitotoxicidade indicam haver interação do uso de dietholate e o herbicida clomazone para a cultura do milho. Outros trabalhos confirmam a interação do uso de antídotos nas culturas da aveia-branca (Codd, 1986), milho (Boldt \& Barret, 1991; Simarmata \& Penner, 1993; Kotoula-Syka \& Hatzios, 1996; Hinz et al., 1997; Sprague et al., 1999) e sorgo (Simarmata \& Penner, 1993), com melhorias na seletividade de diferentes compostos químicos, sendo que o aumento da desintoxicação dos herbicidas através do acréscimo da atividade enzimática, responsável pela degradação destes, foi o principal mecanismo para redução dos sintomas dos produtos. De acordo com Hatzios (1983), um aumento na detoxificação do herbicida induzida pelo antídoto parece ser o maior mecanismo envolvido na ação protetora do mesmo, com a indução de reações de oxidação que possivelmente estão envolvidas nessa proteção. Uma hipótese alternativa envolve o aumento da conjugação da glutationa com o herbicida, induzida pelo antídoto (Fuest \& Cronwald, 1986). Esses resultados contradizem os resultados obtidos por Rizzardi \& Serafini (2001), que não verificaram a ação do anidridico naftálico como protetor de plantas de aveia-branca aos herbicidas diclofop, sulfentrazone, isoxaflutole e clomazone.

O acúmulo de matéria seca não apresentou alterações nos primeiros dias após a emergência das plantas. Ressalta-se que as amostras para a determinação da matéria seca não foram realizadas somente nas plantas verdes, mas também nas plantas albinas. Resultados semelhantes foram obtidos por Liebl \& Norman (1991), quando observaram que concentrações que inibiram o teor de clorofila não afetaram o acúmulo de matéria fresca de plantas de milho e caruru. As diferenças no acúmulo de matéria seca aérea das plantas de milho, tratadas ou não com dietholate, foram observadas a partir da dose de $500 \mathrm{~g} \mathrm{ha}^{-1}$ de clomazone (Figura $1 \mathrm{C}$ ). O herbicida clomazone é absorvido predominantemente pelo meristema apical das plântulas, pelas raízes e colo das plantas, translocado via xilema para as folhas, causando inibição dos compostos precursores do pigmento fotossintético, determinando redução do nível de caroteno e fitol e, conseqüentemente, de clorofila. Uma vez que o caroteno protege a clorofila da destruição pela luz solar, o modo de ação do produto torna-se bi-direcional, inibindo a produção de clorofila e a produção de pigmentos protetores da mesma (Figura 2). As plantas emergem brancas, por falta de clorofila, e morrem em pouco tempo (Devine et al., 1993; Rodrigues e Almeida, 1998). Reduções de $80 \%$ e $90 \%$ no acúmulo da matéria seca aérea foram detectadas na dose de clomazone a $4.000 \mathrm{~g} \mathrm{ha}^{-1}$, em plantas provenientes de sementes tratadas ou não com dietholate, respectivamente (Figura 1C e 1D).

O teor de clorofila foi reduzido em $50 \%$ nas plantas provenientes de sementes não tratadas com dietholate, em função de $784 \mathrm{~g} \mathrm{ha}^{-1}$ de clomazone, enquanto que nas plantas provenientes de sementes tratadas com dietholate essa redução foi obtida apenas com $1.740 \mathrm{~g} \mathrm{ha}^{-1}$ de clomazone (Figura 4).

No experimento in vitro, o teor de clorofila diminuiu a partir da menor dose avaliada (4 ppm), sendo observadas reduções de 31,1 e $83,9 \%$ para as plantas provenientes de sementes tratadas ou não com dietholate, respectivamente (Figura 5). A partir de 8 ppm, observou-se acentuada clorose das plantas de milho não tratadas com dietholate, com redução acima de $90 \%$, enquanto que nas plantas de milho tratadas com dietholate as reduções foram de $48 \%$ (Figuras 5 e 3 ). 


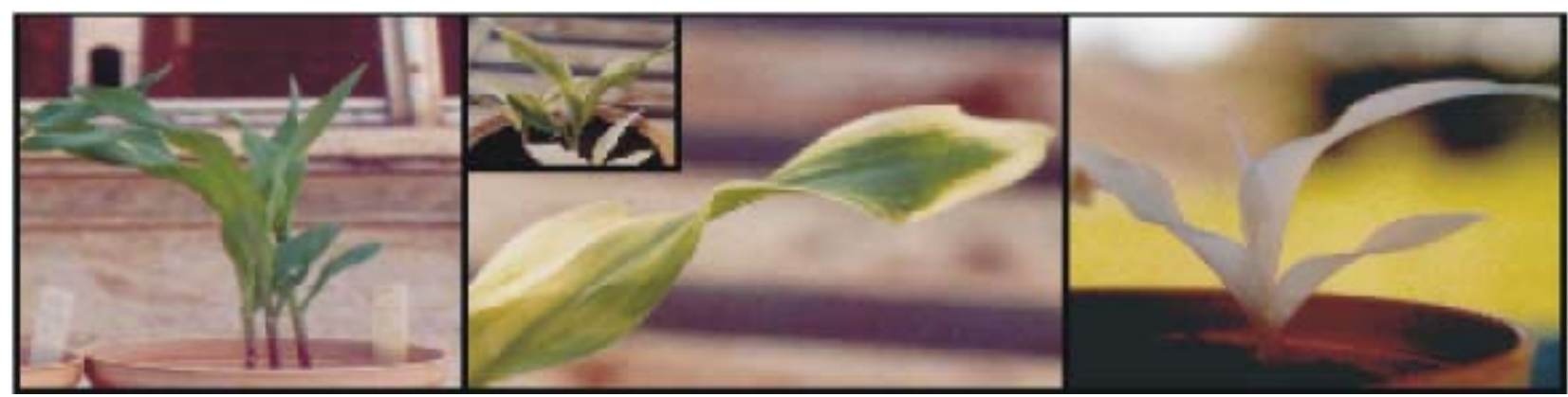

FIGURA 2. Efeito fitotóxico de clomazone em plantas de milho. Embrapa Milho e Sorgo, Sete Lagoas, MG, 2002.

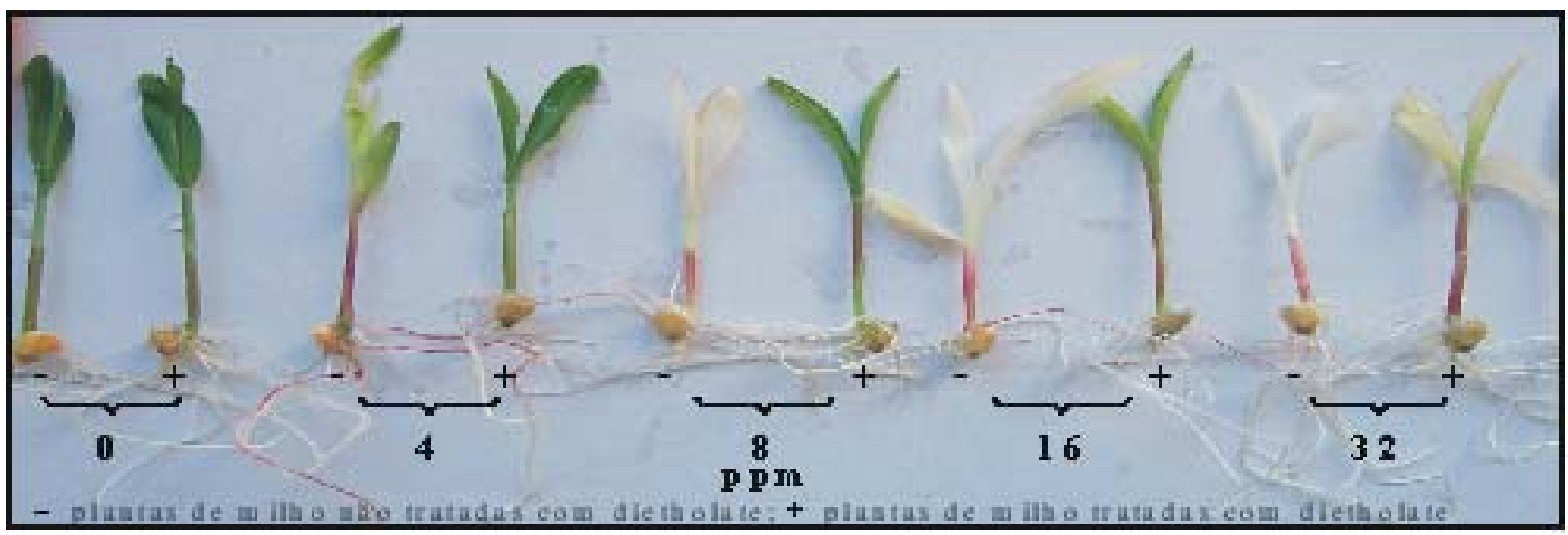

FIGURA 3. Efeito de clomazone no teor de clorofila em plantas de milho BRS 2223 cultivadas in vitro. Embrapa Milho e Sorgo, Sete Lagoas, MG, 2002.

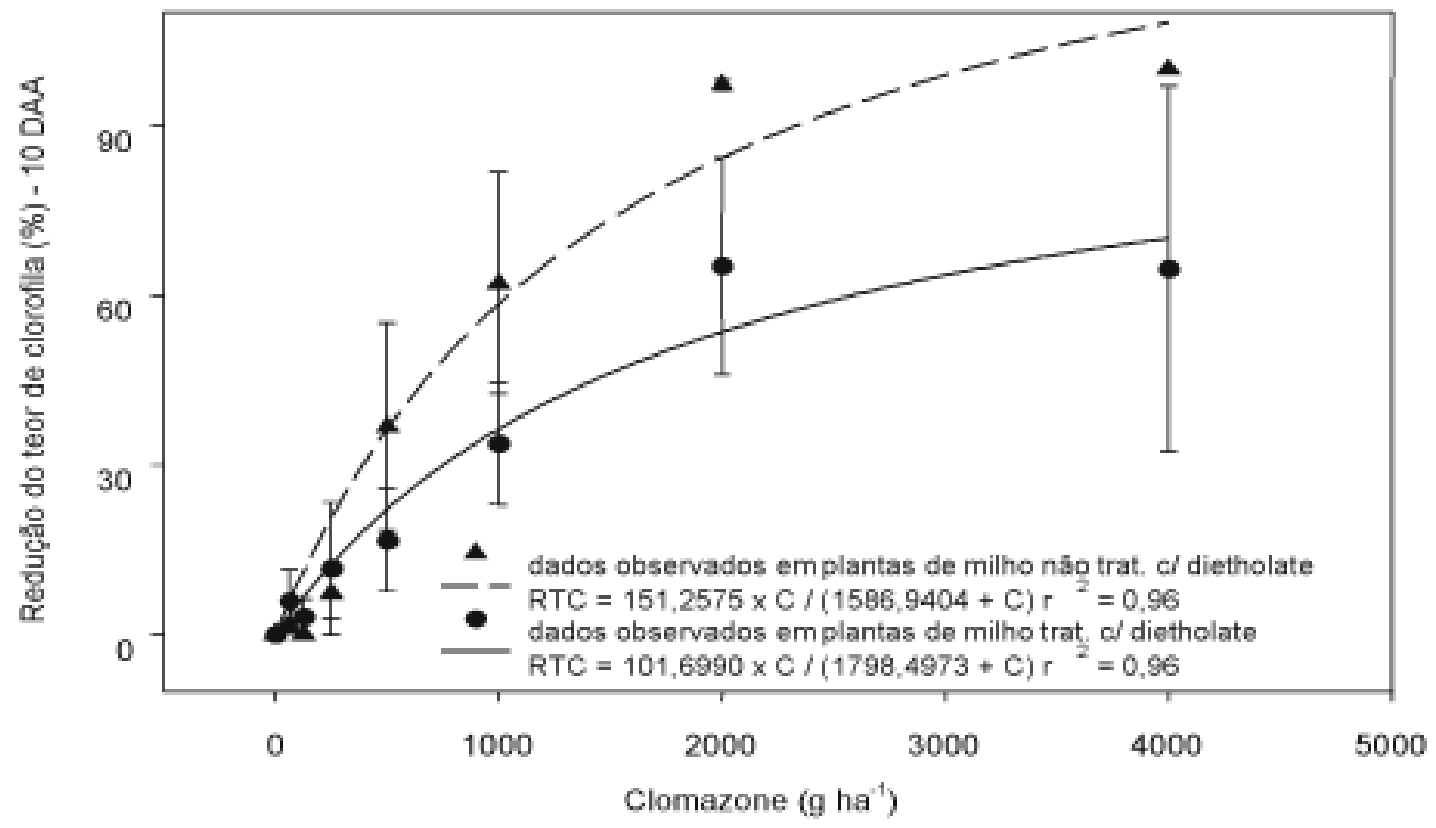

FIGURA 4. Redução do teor de clorofila aos 10 DAA de clomazone em plantas de milho provenientes de sementes tratadas ou não com dietholate. Embrapa Milho e Sorgo, Sete Lagoas, MG, 2002. 


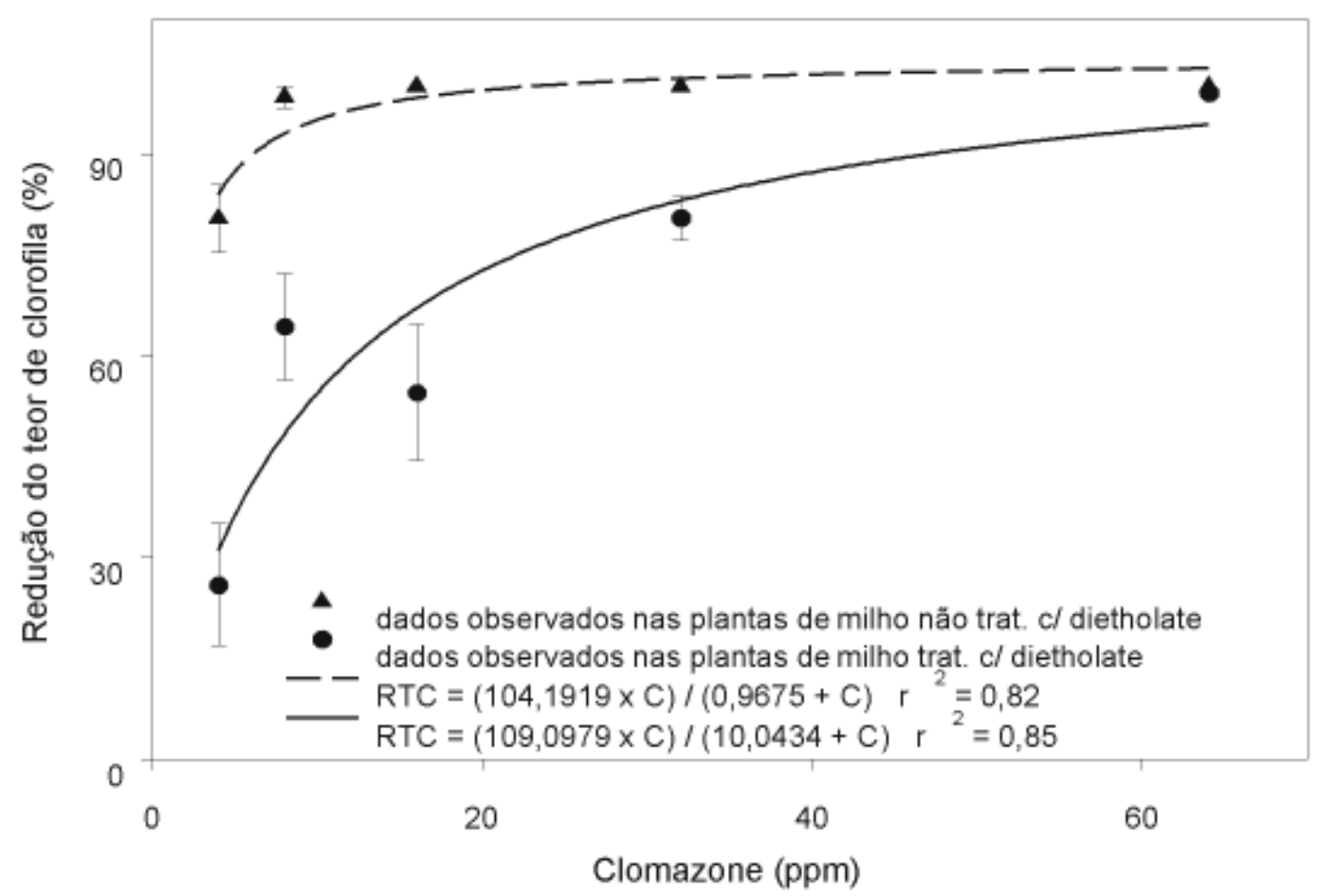

FIGURA 5. Redução do teor de clorofila aos 10 DAA de clomazone em plantas de milho provenientes de sementes tratadas ou não com dietholate. Embrapa Milho e Sorgo, Sete Lagoas, MG, 2002.

Embora os resultados tenham demonstrado que o tratamento das sementes com dietholate diminuíram os efeitos fitotóxicos da aplicação de clomazone nas plantas de milho, ressalta-se a necessidade de mais estudos, visando avaliar o efeito do armazenamento de sementes tratadas com dietholate e do efeito de chuvas após o plantio e a aplicação de clomazone.

\section{Conclusões}

Em função dos resultados observados, pode-se inferir que dietholate apresenta potencial para proteger plantas de milho dos efeitos fitotóxicos do herbicida clomazone, diminuindo a sensibilidade das plantas à aplicação do herbicida.

\section{Literatura citada}

BRASIL, Ministério da Agricultura, Pecuária e Abastecimento. Disponível em http:// www.agricultura.gov.br. Acesso em: 20 jun.2002.
BOLDT, L. D.; BARRET, M. Reducing imazethapyr injury to field corn (Zea mays) with naphthalic anhydride. Weed Science, Lawrence, v. 39, n. 4, p. 640-643, 1991.

CODD, T. M. 1,8 Naphthalic anhydride as a herbicide safener for cultivated oats. Pesticide Science, Oxford, v. 17, n. 1, p. 60, 1986.

DAVIES, J.; CASELEY, J. C. Herbicide safeners: a review. Pesticide Science, Oxford, v.55, n.11, p. 1043-1058, 1999.

DEUBER, R. Herbicidologia. In: DEUBER, R. Ciência das plantas daninhas: fundamentos. Jaboticabal, FUNEP, 1992.

DEVINE, M. D.; DUKE, S. O.; FEDTKE, C. Safeners for Herbicides. In: DEVINE, M. D.; DUKE, S. O.; FEDTKE, C (Ed.), Physiology of Herbicide Action. Englewood Cliffs: Prentice Hall, 1993. p. 376-387. 
FUEST, E. P.; CRONWALD, J.W. Induction of rapid metabolism of metolachlor in sorghum (Sorghum bicolor) shoots by CGA-92194 and other antidotes. Weed Science, Ithaca, v.34, p. 354-361, 1986.

HATZIOS, K.K. Herbicide antidotes: development, chemistry and mode of action. Advances in Agronomy, New York, v.36, p. 165-316, 1983.

HESS, F. D.; WELLER, S. C. Principles of selective weed control with herbicides. In: Herbicide Action: an intensive course of the activity, selective, behavior, and fate of herbicides in plants and soils. West Lafayette: Purdue University, 2000. p. 112-134.

HINZ, J. R. R.; OWEN, M. D. K.; BARRET, M. Nicosulfuron, pirimisulfuron, and bentazon hydroxylation by corn (Zea mays), woolly cupgrass (Eriochloa villosa), and shattercane (Sorghum bicolor) citochrome P-450. Weed Science, Lawrence, v. 45, n. 4, p. 474-480, 1997.

HOFFMAN, O. L. Chemical seed treatments as herbicide antidotes. Weeds, Ithaca, v. 10, p. 32, 1962.

KOTOULA-SYKA, E.; HATZIOS, K.K. Interactions of tribenuron with four safeners and piperonyl butoxide on corn (Zea mays). Weed Science, Lawrence, v.44, n.2, p. 215-218, 1996.

LIEBL, R. A.; NORMAN, M. A. Mechanism of clomazone selectivity in corn (Zea mays), soybean (Glycine max), smooth pigweed (Amaranthus hybridus), and velvetleaf (Abutilon theophrasti). Weed Science. Lawrence, v. 39, 1991.p. 329-332.
MURASHIGE, T.; SKOOG. F. A revised medium for rapid growth and bio-assays with tobacco tissue culture. Physiologia Plantarum, Copenhagen, v.15, p.473-497,1962.

OLIVEIRA JUNIOR, R.S. Seletividade de herbicidas para culturas e plantas daninhas. In: OLIVEIRA JNIOR, R.S.; CONSTANTIN, J. Plantas daninhas e seu manejo. Guaíba: Agropecuária, 2001. p. 291-313.

RIZZARDI, M. A.; SERAFINI, M.C. Ação do anidrido naftálico na seletividade de herbicidas aplicados para controle de azevém em aveia-branca. Planta Daninha, Campinas, v.19, n.3, p. 367-374, 2001.

RODRIGUES, B. N.; ALMEIDA, F. S. Clomazone. In: ALMEIDA, F.S. de; RODRIGUES, B.N. Guia de Herbicidas. 4.ed. Londrina: PR, 1998. p. 137-142.

SIMARMATA, M.; PENNER, D. Protection from primulsulfuron injury to corn (Zea mays) and sorghum (Sorghum bicolor) with herbicide safeners. Weed Technology, Lawrence, v. 7, p. 174-179, 1993.

SPRAGUE, C. L.; PENNER, D.; KELLS, J. J. Enhancing the margin of selectivity of RPA 201772 in Zea mays with antidotes. Weed Science, Lawrence, v. 47, n 5, 1999. p. 492-497.

STEEL, R. G. D.; TORRIE, J. H. Principles and procedures of statistics: a biometric approach. New York: McGraw-Hill, 1997. 663p. 